\title{
IMPLICAÇÕES GEOPOLÍTICAS E GOVERNANÇA AMBIENTAL NA REGULAMENTAÇÃO DA INDC BRASILEIRA
}

\author{
GEOPOLITICAL IMPLICATIONS AND ENVIRONMENTAL \\ GOVERNANCE IN THE REGULATION OF THE BRAZILIAN INDC
IMPLICACIONES GEOPOLÍTICAS Y GOBERNANZA AMBIENTAL EN LA REGULACÍON DE LA INDC BRASILEÑA \\ Carlos Germano Ferreira Costa - Universidad Politécnica de Madrid - Madrid - Espanha \\ carloscostainspira@gmail.com
}

\section{Resumo}

As mudanças climáticas representam uma ameaça para as sociedades humanas e os ecossistemas naturais se tornando uma questão de segurança nas recentes discussões políticas. No entanto, a sensibilização e participação pública, e interesse político variam entre os países membros da Convenção - Quadro das Nações Unidas sobre a Mudança do Clima (UNFCCC). Confrontado com o risco iminente de mudanças, a comunidade internacional necessita repensar questões de ordem geopolítica e governança ambiental cuidadosamente. Este artigo busca avançar o diálogo sobre governança e segurança climática através da análise do processo que levou, no Brasil, à criação da pretendida Contribuição Nacionalmente Determinada (INDC) no contexto das negociações de um protocolo com força legal sob a Convenção do Clima. Com essa abordagem, ao dissecar estratégias de mitigação e adaptação às mudanças climáticas compreendidas a partir de implicações políticas e espaciais, e explorar fatores-chave associados com as percepções públicas, sensibilização, ética, justiça, e de risco. Concluimos que as implicações normativas da regulamentação ambiental brasileira relacionadas ao clima, relações internacionais e geopolítica se interconectam como um ponto de partida para compreender o que está em jogo, a tentativa Brasileira de forjar liderança global em questões ambientais e repensar pressupostos geopolíticos tradicionais.

Palavras-chave: Mudanças Climáticas, Desenvolvimento Sustentável, Comunidade Internacional, Governança Ambiental Global.

\section{Abstract}

Climate change is a threat to human societies and natural ecosystems and it has become a security issue in the recent political discussions. However, awareness and public participation, and political interests vary greatly among the UNFCCC Parties. Faced with imminent risks the international community needs to rethink geopolitical issues and environmental governance carefully. This article seeks to advance the debates on environmental governance and climate security by analyzing the process that led, in Brazil, to the creation of the Intended Nationally Determined Contribution (INDC) in the context of an international agreement with legal force under the Climate Convention. Based on that,dissecting actions related to mitigation and adaptation strategies to climate change based on political and spatial questions; and exploring key-factors associated with public perceptions, awareness, ethics, justice, and risk. We conclude that the normative implications of the Brazilian environmental regulation related to the climate, the international relations and the geopolitics interconnect as a starting point for understanding what is at stake, the Brazilian attempt to forge global leadership on environmental issues and to rethink traditional geopolitical assumptions.

Keywords: Climate Change, Sustainable Development, International Community, Global Environmental Governance. 


\section{Resumen}

El cambio climático representa una amenaza para las sociedades humanas y los ecosistemas naturales y se ha convertido en un problema de seguridad en las recientes discusiones políticas. Sin embargo, la conciencia y la participación del público, y los intereses políticos varían entre los países miembros de la The United Framework Convention on Climate Change (UNFCCC). Frente a los riesgos inminentes de cambios, la comunidad internacional necesita repensar cuestiones de orden geopolítica y gobernanza ambiental con cuidado. En esta investigación se busca avanzar en los debates sobre la gobernanza ambiental y la seguridad climática mediante el análisis del proceso que llevó, en Brasil, a la creación de la pretendida Contribución Nacionalmente Determinada (INDC) en el contexto de las negociaciones de un protocolo con fuerza legal bajo la Convención del Clima. Con ese abordaje, al diseccionar estrategias de mitigación y adaptación a los cambios climáticos basada en cuestiones políticas y espaciales, y explorar factores-clave asociados con las percepciones públicas, sensibilización, ética, justicia, y de riesgo. Llegamos a la conclusión de que las implicaciones normativas de la regulación ambiental brasileña relacionada con el clima, las relaciones internacionales y geopolítica se interconectan como un punto de partida para comprender lo que está en juego, el intento Brasileño en forjar el liderazgo mundial en las cuestiones ambientales y repensar de los presupuestos geopolíticos tradicionales.

Palabras clave: Cambios Climáticos, Desarrollo Sostenible, Comunidad Internacional, Gobernanza Ambiental Global.

\section{Introdução}

As mudanças climáticas representam um tema urgente sendo entendido essencialmente como um problema coletivo, mas que demanda ações individuais. Um fato que tem profundo significado e reflexos para a sustentabilidade do desenvolvimento e de políticas nacionais de curto, médio e longo prazos, não somente ou diretamente relacionadas às questões geográficas em si, mas ao fato das implicações políticas e sociais serem refletidas de modo distinto em cada porção do território e nas respostas sociais como reflexo da adoção de políticas nacionais e internacionais. Se porventura houver falhas marcantes nesse processo, no que concerne ações de mitigação e adaptação fundamentadas nas respectivas responsabilidades e capacidades de cada país, a resposta às mudanças climáticas não será ambiciosa o suficiente para evitar os impactos catastróficos e a ampliação de injustiças e desigualdades atuais. Segundo o $5^{\circ}$ Relatório do IPCC, para garantirmos dois terços de chance de evitar que o aquecimento global, até o ano 2100, ultrapasse os $2^{\circ} \mathrm{C}$ em relação à era pré-industrial, será necessário limitar as emissões globais acumuladas em $1.000 \mathrm{Gt} \mathrm{CO}_{2}$, no período de 2012 a 2100, reduzindo as emissões entre $40 \%$ e $70 \%$ até 2050 (mantendo concentrações de $\mathrm{CO}_{2}^{-\mathrm{e}}$ ao redor de $450 \mathrm{ppm}$ ), chegando próximo a zero ou com emissões negativas após esse ano, em relação aos níveis de 2010 (AR5, 2014, p. 20). Essa pesquisa argumenta que, os melhores esforços para avaliar a capacidade e responsabilidade brasileira 
nesse âmbito e suas implicações relativas passa por considerar a extensão do debate regulatório e implicações normativas no contexto de negociações nacionais e internacionais para ilustrar a complexidade envolvida que ditam as implicações e repercussões geopolíticas (i.e. políticas, espaço, ambiente e população etc.) e de governança ambiental. Esse estudo é "stakeholder-orientado", fundamentado em investigação interdisciplinar e transdisciplinar, em multinível com base em teorias de governança participativa e filosofia política, com foco na integração horizontal de processos de ordem política e ambiental, bem como questões de legitimidade, prestação de contas e sustentabilidade, com base na análise de fontes secundárias (texto, números, imagens, relatórios, comunicados, Leis, Decretos etc.). O objetivo, nesse sentido, é vincular questões geopolíticas a questões nacionais de discurso e identidade através das reivindicações, e quadros-chaves normativos, sobre as alterações climáticas através da análise crítica do discurso oficial do governo brasileiro e unidades da federação, de organizações internacionais e de institutos de pesquisas renomados, principalmente entre 2009 e 2015 que culminam, no Brasil, com a elaboração da pretendida Contribuição Nacionalmente Determinada (Intended Nationally Determined Contribution - INDC) no contexto das negociações de um protocolo com força legal sob a Convenção do Clima, e; assim, analisar criticamente as implicações das posições tomadas para compreender o que está em jogo com a INDC brasileira - a tentativa de forjar liderança global em questões ambientais e influenciar uma nova geopolítica climática.

\section{As Mudanças Climáticas e "Geopolítica”}

Haldén (2007, p. 43) afirma que, no sentido mais amplo, a geografia é a disciplina que estuda a interface entre os sistemas naturais e sociais, tais como a economia, agricultura e planejamento urbano para citar apenas algumas atividades humanas afetadas pela necessidade de adaptação e mitigação frente às mudanças climáticas; ele defende ainda que a interface mais específica entre geografia e política é, por sua vez, representada pela subdisciplina "geografia política" e às vezes por sua rival, a "geopolítica". Como não é interesse desse artigo perder-se em definições conceituais sobre essa temática utilizaremos conceito mais amplo de "geopolítica" numa perspectiva normativa de "alta política”. Conforme defende Dalby (2013a, p. 39), 
as mudanças climáticas têm uma forte conexão com geopolítica. Porém, agora, a humanidade está determinando o seu futuro climático - mesmo que não intencionalmente -, e dessa forma, essas alterações exigem um repensar político em face das inúmeras transformações que estão tornando o planeta "artificial" na era do antropoceno. Da mesma forma que Clark (2014, p. 20), ao sugerir que a problematização atual de "condições planetárias de fronteira" - as mudanças climáticas não respeitam fronteiras - possam ser tomadas como indicativo do surgimento de um novo tipo de "política geológica" que esteja mais orientada à dinâmica temporal e mudanças de estado dos sistemas da Terra do que com questões políticas convencionais que giram em torno de territórios e fronteiras físicas -, uma "geopolítica" que também levantaria questões sobre a experimentação prática com processos terrestres. Conforme provoca Simon Dalby (2013b, p. 37), ao afirmar que a geopolítica deve, não somente considerar sistemas terrestres seriamente, mas também toda a dinâmica envolvida nesse processo, corroborando mais uma vez com Clark (2014, p. 38) que reforça a necessidade de se trabalhar além da tradicional ótica geopolítica confrontando os desafios futuros dessa disciplina. Há a necessidade de se repensar criticamente o modo como compreendemos as mudanças climáticas sob as óticas científica, social e política (Dalby, 2015, p. 22).

\section{A Caracterização das Emissões de Gases do Efeito Estufa (GEE) no Brasil}

O Brasil é um país de dimensões continentais, que apresenta uma economia complexa e dinâmica - apesar da recente crise política e econômica enfrentada pela nação após 2010 - bem como representando um país rico em recursos naturais e um grande produtor agrícola, com imensa população, entretanto, ainda sendo reconhecido como um país em desenvolvimento. Não obstante, o Brasil se encontra entre os dez maiores países emissores de GEE, apresentando emissões que oscilam entre 3 a 7\%,das emissões globais, ao longo dos últimos anos - 4,6\% (1990), chegando a 7\% (1997) e se reduzindo a 3\% (2012) -,é, ainda assim, o segundo maior emissor pela produção agropecuária - com 418 Gt equivalentes de $\mathrm{CO}_{2}$ emitidos em 2013, o que representa quase um terço das emissões nacionais(WR, 2015, p. 1; SEEG, 2015, p. 10 e 27). Para o ano de 2005, suas emissões foram estimadas em $2.193 \mathrm{MtCO}_{2}{ }^{-e q}$, enquanto que suas emissões projetadas, mantendo o padrão "Business-As-Usual” (BAU), ou seja, sem a 
adoção de políticas ou programas de mitigação, estão estimadas em 3.126 $\mathrm{MtCO}_{2}{ }^{- \text {eq }}$ para o ano de 2020 (Halonen et al., 2013, p. 24-25; MF, 2014, p.13). Mesmo assim, diante desse cenário, o Brasil tem sido considerado como integrante do grupo "Non-Annex I" (UNFCCC, 2014). E, ao invocar o artigo 3 da UNFCC, com base em questões de equidade fundamentando-se na abordagem das "comuns mas diferenciadas responsabilidades e respectivas capacidades”, alega não possuir obrigações legais de limitação ou redução de emissões quantificadas e, dessa forma, demanda das nações mais desenvolvidas liderança nas ações de mitigação e adaptação, baseada em suas contribuições históricas e respectivas capacidades, para alcançar os objetivos do Protocolo de Kioto (McManus, 2009, p. 2).

Entretanto, o Brasil na busca por apresentar ao mundo seu novo status geopolítico, reconhece-se como o maior emissor de gases de efeito estufa na América Latina e Caribe, e ao almejar uma posição de liderança no cenário internacional, na tentativa de se apropriar das negociações climáticas a seu favor, anunciou metas voluntárias de redução de emissões que variam de $1.500 \mathrm{MtCO} 2 \mathrm{eq}$ a $2.000 \mathrm{MtCO} 2 \mathrm{eq}$, com vista a reduzir as suas emissões projetadas até 2020, conforme a Segunda Comunicação Nacional do Brasil à UNFCCC e da Política Nacional sobre Mudança do Clima, regulamentada por meio da Lei $\mathrm{n}^{0} 12.187 / 2009$ e pelo Decreto $\mathrm{n}^{0}$ 7.390. Por meio da referida Lei, previu-se a elaboração de planos setoriais com a inclusão de ações, indicadores e metas específicas de redução de emissões e mecanismos para a verificação do seu cumprimento para guiar cada setor: Agropecuária, Energia, Processos Industriais, Tratamento de Resíduos e Uso da Terra e Florestas. O Governo Brasileiro oficializou, assim, sua posição na COP-15, junto à Convenção-Quadro da ONU sobre Mudança do Clima com planos setoriais, então conhecidos por NAMAs (Ações de Mitigação Nacionalmente Apropriadas) definidos como forma de colocar em prática as metas de mitigação e adaptação de cada setor como compromisso inicial de reduzir as emissões nacionais de GEE entre 36,1\% e 38,9\% - considerando emissões projetadas até 2020 de 3.236 Mt CO2 - tendo inicialmente estabelecido o ano de 1990 como base (SEEG, 2015, p. 30).

\section{Os compromissos Brasileiros de Redução de Gases de Efeito Estufa}

O Governo da República Federativa do Brasil comunicou, em Outubro de 2015, ao UNFCCC, sua pretendida Contribuição Nacionalmente 
Determinada (intended Nationally Determined Contribution - INDC), no contexto das negociações de um instrumento jurídico universal vinculante que visa respeitar plenamente os princípios e dispositivos da Convenção, em particular o "princípio" das comuns, mas diferenciadas responsabilidades e respectivas capacidades (itamaraty, 2015, p. 1). Uma longa trajetória de discussões e negociações culminou no referido documento que tem como escopo propor meios de mitigar, adaptar e implementar ações de maneira consistente com o propósito de alcançar o objetivo último da Convenção, nos termos da decisão 1/CP.20, parágrafo 9 (Chamado de Lima para Ação Climática). Desse modo, a INDC brasileira aborda medidas de mitigação e adaptação, bem como de necessidades financeiras, tecnológicas e de capacitação, para responder aos desafios das mudanças climáticas que podem representar até $43 \%$ de redução das emissões nacionais de GEE até 2030 - Este documento reconhece fortemente o importante papel dos governos locais (Itamaraty, 2015, p. 4).

O processo que resultou na elaboração da INDC refletiu tanto o amadurecimento político quanto o técnico do governo brasileiro e das instituições envolvidas e foram pautados em base realista, já que o país reduziu em mais de 41\% (GWP-100) as emissões de GEE entre 2005 e 2012. De acordo com Cole e Liverman (2015, p. 1), no Brasil, as prioridades relacionadas com desenvolvimento são tratados através de medidas substanciais, enquanto as preocupações sociais e ambientais são abordadas através de mecanismos processuais, incluindo a participação. Isso, talvez, demonstre a forma como o processo de governança ambiental no Brasil, tanto internamente quanto no contexto dos regimes multilaterais de negociação climática, foram geridos. Desde os primórdios das discussões e negociações, e das primeiras ações e atividades relacionadas às mudanças climáticas no Brasil, instituições foram criadas para abordar a implementação nacional da Convenção do Clima.

Em junho de 1994, o governo brasileiro estabeleceu a Comissão Interministerial para o Desenvolvimento Sustentável - CIDES - por decreto presidencial (Decreto $\mathrm{n}^{\circ} 1.160$ de 21 de junho de 1994). O objetivo da CIDES foi prestar assistência ao Presidente da República na tomada de decisões estratégicas e elaboração de políticas nacionais de desenvolvimento sustentável, de forma compatível com a Agenda 21, em reconhecimento da complexidade desta tarefa e da necessidade de envolvimento de um grande número de instituições (MCTI, 2004, p. 59). Além disso, a preocupação 
por maior institucionalização sobre questões das mudanças relacionadas ao clima levou à criação, pelo Decreto Presidencial de 07 de julho de 1999, da Comissão Interministerial de Mudança Global do Clima, com o objetivo de coordenar as ações do governo nesta área - Decreto s/n $\mathrm{n}^{\circ}$ de 7 de julho de 1999 com a posterior publicação de seu Regimento Interno pelo Portaria $\mathrm{n}^{\mathrm{o}}$ 533, de 29 de agosto de 2000. Este decreto habilitou a Comissão a solicitar a colaboração de outras entidades públicas ou privadas e as organizações representativas da sociedade civil na execução das suas responsabilidades (MCTI, 2004, p.60).

O governo brasileiro estabeleceu ainda, pelo Decreto $\mathrm{n}^{\circ} 3.515$, de 20 de junho de 2000, o Fórum Brasileiro de Mudanças Climáticas (FBMC), que visava sensibilizar e mobilizar a sociedade para a discussão e posição sobre os problemas decorrentes da mudança do clima causada pelos gases do efeito estufa, bem como subsidiar as dicussões e a implementação do Mecanismo de Desenvolvimento Limpo (MDL) definidos no Artigo 12 do Protocolo de Kioto pela UNFCCC, e ratificado pelo Congresso Nacional por meio do Decreto Legislativo $\mathrm{n}^{0}$ 1, em 3 de fevereiro de 1994. O FBMC foi criado para auxiliar o governo brasileiro na incorporação de questões sobre as alterações climáticas em diferentes estágios de ordem pública (FBMC, 2015). Por sua vez, o Ministério das Relações Exteriores (MRE), vem coordenando consultas públicas periódicas com a sociedade civil brasileira com a função de apoiar a proposta brasileira (INDC), apresentada recentemente, para o novo acordo ao abrigo da Convenção do Clima (MRE, 2014; Portal Brasil, 2014). Quanto às políticas nacionais, com o lançamento do Plano ABC em 2010, houve a possibilidade de dar início a implementação de práticas de mitigação das emissões de GEE pela agropecuária nacional e outros setores da economia. Incorporado ao Plano Safra, a linha de crédito Programa ABC buscou financiar a adoção de práticas de baixo carbono, como a recuperação de pastagens degradadas e integração lavoura-pecuária-floresta. Contudo, menos de 1,6\% do orçamento do Plano Safra 2015/2016 é destinado ao Programa ABC (SEEG, 2015, p. 7).

A República Federativa do Brasil é dividida em 26 estados, 5.565 municípios e o Distrito Federal, onde o capital da República, Brasília, sede do governo e do Executivo, Legislativo e Judiciário, está localizado (IBGE, 2015). A nível subnacional, 17 das 27 unidades federativas brasileiras já sancionaram leis que estabelecem, em nível de Estado, políticas de mudanças climáticas e quatro legislaturas estaduais estão considerando projetos 
de lei que estão em discussão com a sociedade civil, enquanto 16 criaram um respectivo Fórum Estadual de Mudanças Climáticas, todos entre 2005 e 2009 (Fórum Clima, 2012, p. 10-11). Entretanto, a maioria dessas políticas atualmente em vigor não estabeleceram metas de redução de emissões de GEE - as exceções são os estados de São Paulo (Lei n ${ }^{0}$ 13.798, de 9/11/2009), Rio de Janeiro (Lei n ${ }^{0}$ 5.690, de 14/04/2010) e Paraíba (Lei $n^{\circ} 9.336$, de 31/01/2011). O Estado de São Paulo estabeleceu um objetivo absoluto de redução das emissões de GEE em 20\% até 2020, em comparação a 2005; enquanto o estado da Paraíba definiu a mesma meta inicial do governo federal: a redução das emissões de GEE projetadas entre 36,1\% - 38,9\% em 2020. O estado do Rio de Janeiro estabeleceu uma intensidade de emissão alvo (tCO2e/PIB) em 2030 equivalente à intensidade observada em 2005, e também estabeleceu metas de redução, em setores específicos, variando de 30 a 65\% - Decreto $n^{\circ}$ 43.216/2011, Lei $n^{\circ}$ 5.690/2010; Plano Estadual sobre Mudança do Clima; Resoluções $n^{\circ}$ 43, 64 e 65, entre outros (Governo do Estado do Rio de Janeiro, 2015). Entretanto, apenas oito unidades federativas assumiram o compromisso de estabelecer metas em regramentos específicos, e outras três unidades federativas têm mostrado intenções para reduzir ou pelo menos estabilizar suas emissões de GEE (Fórum Clima, 2012, p. 17). Além disso, é necessário observar que o financiamento da implementação das políticas estaduais de mudanças climáticas inclui, em geral, mecanismos de crédito e financiamento. Nesse quesito, somente 15 Estados fizeram alguma referência a fundos estaduais, sendo que destes, apenas nove abordam questões específicas para mudanças climáticas, que somados ao Fundo Nacional sobre Mudanças do Clima - criado pela Lei $\mathrm{n}^{\circ}$ 12.114/2009 e regulamentado pelo Decreto $n^{\circ} 7.343 / 2010$-, têm por finalidade financiar projetos, estudos e empreendimentos que visem à mitigação (ou seja, à redução dos impactos) das mudanças do clima e à adaptação a seus efeitos (MMA, 2015). Por outro lado, dos 17 Estados que possuem legislação sancionada ou projeto de lei que define a política estadual de mudanças climáticas, apenas 12 mencionam a existência de processos de licenciamento ambiental para regular suas políticas: Amapá, Amazonas, Pará, Tocantins, Pernambuco, Goiás, Mato Grosso, Espírito Santo, Rio de Janeiro, São Paulo, Rio Grande do Sul e Santa Catarina, apensar de não existir padronização nesse processo (Fórum Clima, 2012, p. 19).

Atualmente, o Plano Nacional de Adaptação à Mudança do Clima (PNA) - um instrumento elaborado pelo governo federal em colaboração 
com a sociedade civil, setor privado e governos estaduais que tem como objetivo promover a redução da vulnerabilidade nacional às mudanças do clima e à gestão de risco associado a esse fenômeno - entrou em consulta pública pela internet por 45 dias contados a partir do dia 8 de Outubro de 2015, caracterizando, como pioneira, a posição brasileira no âmbito da governança climática e envolvendo a participação de diversos ministérios, além do Fórum Brasileiro de Mudanças Climáticas (PNA, 2015).

\section{A Dinâmica das emissões Brasileiras de GEE}

Comparativamente ao resto do mundo, a dinâmica das emissões globais Brasileiras pode ser dividida em quatro fases: entre 1990 e 1997 as emissões totais no Brasil cresceram em um ritmo maior que as emissões globais; no período seguinte, entre 1998 e 2004, as emissões cresceram num ritmo similar ao das emissões globais, e; após 2005, elas se descasam e apresentam uma forte redução enquanto no resto do mundo elas crescem. Curiosamente, um quarto período parece se formar após 2009 coincidindo com o lançamento da Política Nacional sobre Mudança Climática. Desde então, as emissões pararam de cair e têm-se mantido relativamente estáveis no entorno de 1,5 $\mathrm{Gt} \mathrm{CO}_{2}{ }^{\text {-eq }}$. Nos últimos dois anos, as emissões globais também passaram a desacelerar e podem estar próximas de atingir o seu pico (SEEG, 2015, p. 26).

O relatório "Estimativas Anuais de Emissões de Gases de Efeito Estufa no Brasil no período de 1990 a 2010" - com base no Decreto n7.390/2010 - informa que as reduções das emissões brasileiras, em todos os setores, foi de 38,7\% (de 2,03 para 1,25 bilhão de toneladas de equivalente $\mathrm{CO}^{2}$ ) entre 2005-2010, impulsionado pela redução de emissões de $40,1 \%$ (1995-2005) e 76,1\% (2005-2010) por alterações nos padrões de Uso do Solo, e Florestas (LULUCF), que têm contribuído historicamente com a maior participação do total de emissões no Brasil (em torno de 60\%) (MF, 2014, p. 5; FBMC, 2015). Soma-se a esses dados, o fato do Brasil ter reduzido suas emissões de gases de efeito estufa em mais de 41\% (GWP-100), entre 2005 e 2012, representando a maior redução obtida por qualquer país até agora e, impulsionada pelo uso de matriz energética limpa, o uso de biocombustíveis e declínio significativo na taxa de desmatamento. Fatores que, segundo argumenta o governo, colocam o país no caminho rumo a uma economia de baixo carbono (SECOM, 2015, p. 1). Entretanto 
a redução das emissões de GEE no período 2005-2012 no setor de uso da terra e florestas - de 57,7\% para 14,6\% - esconde uma lógica distorcida que camufla o aumento da contribuição de outros setores da economia nas emissões nacionais de GEE no mesmo período. Na agricultura houve aumento de $20,4 \%$ para $37,1 \%$; no setor de energia, aumento de $16,1 \%$ para $37,1 \%$; na área de processamento industrial, aumento de $3,8 \%$ para $7,1 \%$; e no setor de resíduos sólidos, aumento de 2,1\% para 4,1\% nas emissões de GEE (Ministério do Meio Ambiente, 2015).

\section{0 que está em jogo}

Conforme acredita Haldén (2007, p. 27-28), o clima não é uma causa, mas sim um elemento considerado como uma das condições em que as ações humanas - cultura, economia, política, sociedade etc. -, têm lugar. Portanto as mudanças no clima podem, por sua vez, alterar algumas das outras condições em que os humanos agem. Porém, ele mesmo acredita que as mudanças climáticas não transformarão os sistemas políticos como um todo, mas que estes se adaptarão às mudanças climáticas, ao relembrar que a inclusão dessa temática no discurso político é recente, fazendo parte da rotina das discussões políticas a partir do ano de 2007, quando se deu ênfase ao risco do surgimento de novos conflitos e drásticas alterações nas estruturas políticas. Outra forma de observar essa questão passa por considerar, a exemplo do caso Brasileiro e, conforme defendem Pattberg e Widerberg (2015, p. 685), a ação política na forma de governança ambiental como algo fundamentalmente diferente de períodos anteriores de elaboração de políticas ambientais, já que estamos coletivamente entrando no antropoceno, o que representa uma época de mudanças em escala planetária onde as nossas respostas aos problemas ambientais foram ampliadas significativamente para além dos limites do formal, estando agora, jurídica e legalmente vinculados e negociados em acordos multilaterais para incluir modos de regulação que são muitas vezes transnacionais e de caráter voluntário.

Um aspecto relevante desta posição é que o Brasil como uma economia de transição poderia fornecer insights sobre os sistemas de governança no mundo em desenvolvimento, uma vez que suas ações poderiam influenciar a formulação de políticas em outras nações emergentes (Kesselman et al., 2015, p. 399), e assim, como afirma Kelman (2015, p. 
7) propor que o jogo de mea-culpa seja ainda mais relevante em termos da determinação das questões para as quais a culpa deve ser distribuída, sendo especialmente relevante para o Brasil. Afinal, a Convenção do Clima deve reconhecer que a contribuição relativa dos países emergentes em termos de emissões globais de GEE irá aumentar para satisfazer as suas necessidades sociais e de desenvolvimento. De todo modo, segundo Ferreira Costa (2015, p. 6), o governo brasileiro acredita que tanto suas ações quanto seu compromisso nacional de redução das emissões de GEE (INDCs) estão quantitativamente ligados a um limite de aquecimento atmosférico de $2^{\circ} \mathrm{C}$ graus, o que de alguma forma representa o que o Brasil considera como a sua parcela justa de emissões globais, onde o Brasil parece estar se utilizando de argumentos éticos para forjar liderança moral sobre as negociações climáticas, uma vez que as ações previstas para a sua INDC não são dependentes de apoio externo, apesar de reconhecerem o sucesso de iniciativas como o Fundo Amazônia como forma de captar apoio internacional para a implementação do seu INDC, da mesma forma que reconhecem a importância de esquemas de cooperação SUL-SUL e NORTE/SUL-SUL, no esforço global de combate às alterações climáticas e expansão de suas trocas comerciais.

\section{Considerações Finais}

O discurso político brasileiro parte de uma revisão fundamental que emergiu da necessidade de se adequar às novas circunstâncias mundiais e incorporou as mudanças climáticas, não como um fenômeno determinista, mas como algo a dar forma e expressão diante da construção de uma nova ordem mundial. A emergência de espaços multilaterais de negociação permitiu maior engajamento e representatividade de nações que de outra maneira, como é o caso do Brasil, vinculam sua atuação baseado em questões de ética, justiça e responsabilidade compartilhada a partir da adoção de políticas voluntárias para inserir-se nessas discussões forjando um papel de liderança, que de outro modo não lhe seria permitido, já que careceriam de voz e representatividade. Entretanto, várias questões relevantes emergem a partir da análise do discurso oficial; com, por exemplo, a falta de consenso interno em relação às formas de financiamento e fiscalização das medidas de mitigação e adaptação adotadas por governos locais, assim como o aumento das emissões de GEE em diversos setores 
da economia. Conforme defende essa pesquisa inter- transdisciplinar, não somente para o caso Brasileiro, as mudanças climáticas demandam um entendimento de suas repercussões diante de contextos sócio-políticos e ambientais para que possam ser entendidos como uma possível representação de uma nova "geopolítica".

\section{Tipo de Financiamento}

Erasmus Mundus SMART2 support (Project Reference: 552042-EM-1-20141-FR-ERA MUNDUS-MA2) coordinated by CENTRALESUPELEC.

\section{Referências}

AR5 (Fifth Assessment Report). Climate Change 2014. Synthesis Report Summary for Policymakers, 201. 32 p. Disponível em: <https://www.ipcc.ch/pdf/ assessment-report/ar5/syr/AR5_SYR_FINAL_SPM.pdf >. Acesso em: set. 2015.

BRASIL. Decreto n. 7.343, de 26 de Outubro de 2010. Regulamenta a Lei no 12.114 , de 9 de dezembro de 2009, que cria o Fundo Nacional sobre Mudança do Clima FNMC, e dá outras providências. Presidência da República Federativa do Brasil. Casa Civil Subchefia para Assuntos Jurídicos. Brasília, DF. Diário Oficial da União. 26 out. 2010. Disponível em: <http://www.planalto.gov.br/ccivil_03/_ Ato2007-2010/2010/Decreto/D7343.htm>. Acesso em: abr. 2015.

. Decreto n 7.390 de 9 de Dezembro de 2010. Regulamenta os artigos. 6, 11 e 12 da Lei n 12.187 de 29 de Dezembro de 2009, estabelecendo a Política Nacional de Mudanças Climáticas - PNCC, e dá outras providências. Presidência da República Federativa do Brasil. Casa Civil. Subchefia de Assuntos Jurídicos. Brasília, DF. Diário Oficial da União. 10 dez. 2010. Disponível em:<http://www. planalto.gov.br/ccivil_03/_Ato2007-2010/2010/Decreto/D7390.htm>. Acesso em: maio 2015.

. Decreto Legislativo n. 1, de 03 de Fevereiro de 1994. Ratifica pelo Congresso Nacional o Mecanismo de Desenvolvimento Limpo (MDL) definidos no artigo 12 do Protocolo de Kioto pela UNFCCC. Senado Federal. Diário Oficial da União. Seção I, p. 1.693. 04 fev. 1994. Disponível em: < http://www.bvsde. paho.org/bvsacd/cd38/Brasil/DLeg1-94.pdf>. Acesso em: 15 jan. 2015.

BRASIL. Decreto Presidencial s/n. de 07 de julho de 1999. Comissão Interministerial de Mudança Global do Clima, com o objetivo de coordenar as ações do governo nesta área. Presidência da República Federativa do Brasil. Casa Civil. Subchefia para Assuntos Jurídicos. Diário Oficial da União. 08 jul. 1999. Disponível em: <http://www.planalto.gov.br/ccivil_03/DNN/Anterior\%20a\%20 2000/Dnn07-07-99-2.htm>. Acesso em: mar. 2015.

- Decreto $\mathrm{n}^{\circ} 1.160$, de 21 de Junho de 1994. Cria a Comissão Interministerial para o Desenvolvimento Sustentável (CIDES) e dá outras 
providências. Presidência da República Federativa do Brasil. Casa Civil. Subchefia para Assuntos Jurídicos. Brasília, DF. Diário Oficial da União. p. 9093. Seção 1. 22 jun. 1994. Disponível em: <http://legislacao.planalto.gov.br/legisla/ legislacao.nsf/Viw_Identificacao/dec\%201.160-1994?OpenDocument>. Acesso em: abr. 2015.

. Decreto $n^{\circ}$ 3.515, de 20 de junho de 2000. Cria o Fórum Brasileiro de Mudanças Climáticas (FBMC) e dá outras providências. Presidência da República Federativa do Brasil. Casa Civil. Subchefia para Assuntos Jurídicos. Brasília, DF. Diário Oficial da União. p. 2. Seção 1. 21 jun. 2000. Disponível em: <http://legislacao.planalto.gov.br/legisla/legislacao.nsf/Viw_Identificacao/ DEC\%203.515-2000?OpenDocument>. Acesso em: abr. 2015.

BRASIL. Lei n. 12.114, de 9 de Dezembro de 2009. Cria o Fundo Nacional sobre Mudança do Clima, altera os arts. $6^{\circ}$ e 50 da Lei $n^{\circ} 9.478$, de 6 de agosto de 1997, e dá outras providências. Presidência da República. Casa Civil. Subchefia para Assuntos Jurídicos. Diário Oficial da União. 10 dez. 2009 e retificado em 11 dez. 2009. Disponível em: <http://www.planalto.gov.br/ccivil_03/_Ato20072010/2009/Lei/L12114.htm>. Acesso em: maio 2015.

Lei n. 12.187, de 29 de Dezembro de 2009. Institui a Política Nacional sobre Mudança do Clima - PNMC e dá outras providências. Presidência da república. Casa Civil. Subchefia para Assuntos Jurídicos. Edição Extra. Diário Oficial da União. 30 dez. 2009. Disponível em: <http://www.planalto.gov.br/ ccivil_03/_ato2007-2010/2009/lei/l12187.htm>. Acesso em: maio 2015.

. Portaria n. 533, de 29 de agosto de 2000. Regimento Interno Comissão Interministerial de Mudança Global do Clima. Ministério da Ciência e Tecnologia. 20 de ago. de 2000. 4p. Disponível em: <http://www.cetesb.sp.gov. br/wp-content/uploads/sites/28/2014/08/portaria_n_533_29_08_00.pdf>. Acesso em: ago. 2015.

- IBGE - Instituto Brasileiro de Geografia e Estatística. Brasil em Síntese. População, Trabalho, Contas Nacionais, 2015. Disponível em:<http:// brasilemsintese.ibge.gov.br/>. Acesso em: maio 2015.

. ITAMARATY. Informação Adicional sobre a INDC Apenas para Fins de Esclarecimento. Pretendida Contribuição Nacionalmente Determinada (iNDC) para a Consecução do Objetivo da Convenção-Quadro das nações Unidas sobre Mudança do Clima. República Federativa do Brasil. Brasília - DF. 2015. 10p. Disponível em: <http://www.itamaraty.gov.br/images/ed_desenvsust/BRASILiNDC-portugues.pdf>. Acesso em: ago. 2015.

. Ministério da Ciência, Tecnologia e Inovação - MCTI. Brazil’s Initial National Communication to the United Nations Framework Convention on Climate Change. Secretaria de Pesquisa e Desenvolvimento de Políticas e Programas - SEPED. Coordenação Geral sobre Mudanças Climáticas. Brasília, 2004. 275p. Disponível em: <http://unfccc.int/essential_background/library/ items/3599.php?such=j\&sy mbol=BRA/COM/1\%20B\%20COPY\%201\%20 ENG\#beg>. Acesso em: jun. 2015.

Ministério do Meio Ambiente - MMA. Fundo Nacional sobre Mudança $\bar{d} \bar{c} \bar{C} \overline{l i m a}$ - Fundo Clima. Estabelecido pela Lei n. 12.114/2009 e regulamentado 
pelo Decreto n. 7.343/2010. Meio Ambiente. Disponível em:<http://www.mma. gov.br/apoio-a-projetos/fundo-nacional-sobre-mudanca-do-clima $>$. Acesso em: ago. 2015.

Ministério do Meio Ambiente - MMA. Plano Nacional de Adaptação $\bar{a} \bar{M}$ údança do Clima - PNA. Consulta Pública. 2015. Disponível em: <http:// www.mma.gov.br/clima/adaptacao/plano-nacional-de-adaptacao>. Acesso em: ago. 2015.

- Ministério da Fazenda - MF. Under the Partnership for Market $\bar{R}$ eadiness Program.Market Readiness Proposal. Brasília. aug. 2014. 89 p. Disponível em: <https://www.thepmr.org/system/files/documents/Final\%20 MRP\%20Brazil_29-08-2014.pdf>. Acesso em: ago. 2015.

. Ministério das Relações Exteriores- MRE. Participação da Sociedade Civivil no Processo de Preparação da Contribuição Nacionalmente Determinada do Brasil ao Novo Acordo sob a Convenção-Quadro das Nações Unidas sobre a Mudança do Clima. Relatório Preliminar - Possíveis Opções de Modalidades para a Contribuição Nacional. 25 ago. 2014. 24p. Disponível em: <https://drive. google.com/file/d/0B5FaXljqYTvPWFdVSERoTHY1WWs/edit?pli=1>. Acesso em: ago. 2015.

PORTAL BRASIL. Consulta definirá posição do Brasil em Conferência do Clima. Meio Ambiente. Agência Nacional de Vigilância Sanitária. 27 ago. 2014. Disponível em: <http://www.brasil.gov.br/meio-ambiente/2014/08/ consulta-definira-posicao-do-brasil-em-conferencia-do-clima >. Acesso em: ago. 2015.

. SECOM - Secretaria de Comunicação Social. The Contribution of Brazil to the Paris Climate Agreement. Secretariat of Social Communication of the Presidency of Brazil.International Area. 2015. 2p. Disponível em: <http:// blog.itamaraty.gov.br/images/indc/FactSheet-BrazilINDC.pdf>. Acesso em: ago. 2015.

Clark, N. Geo-politics and the disaster of the Anthropocene. The Sociological Review, v.62, IssueSupplementS1, p.19-37. 2014. Disponível em:<http:/ onlinelibrary.wiley.com/doi/10.1111/sore.2014.62.issue-s1/issuetoc $>$. Acesso em: ago. 2015.

Cole, J.C.; Liverman, D.M. Brazil's Clean Development Mechanism governance in the context of Brazil's historical environment-development discourses. Carbon Management, v.2, i. 2, p. 145-160, 2014.

ferreira Costa, C.G.Brazil's Consideration of Ethics and Justice Issues in Formulating Climate Change Policies. National Climate Justice - Brazil. Joint project of the University of Auckland, School of Architecture and Planning and Widener University, School of Law, Environmental Law Center. p. 9, 2015. Disponível em: < http://nationalclimatejustice.org/2015/10/03/brazil/>.Acesso em: out. 2015.

Dalby, S. Climate Change: New Dimensions of Environmental Security. The Rusi Journal,v.158, i.3, p. 34-43,2013a. Disponível em:<http://www.tandfonline.com/ doi/pdf/10.1080/03071847.2013.807583>. Acesso em: ago. 2015. 
Dalby, S. The geopolitics of climate change. Political Geography ,v. 37, p. 3847, 2013b. Disponível em:<http://www.sciencedirect.com/science/article/pii/ S0962629813000875>. Acesso em: ago. 2015.

Dalby, S.; O’Lear, S.Reframing Climate Change: Constructing ecological geopolitics. London and New York: Routledge, 2015.224 p. Disponível em: <https://www.book2look.com/embed/9781317638643>. Acesso em: set. 2015.

FBMC - Fórum Brasileiro de Mudanças Climáticas. Síntese Reunião FBMC com Presidenta Dilma Rousseff. Palácio do Planalto. Brasília - DF. 05 jun. 2015. Disponível em: <http://www.forumclima.org.br/pt/noticias/sintese-reuniaofbmc-com-presidenta-dilma-rousseff>. Acesso em: ago. 2015.

FORUM CLIMA. O Desafio da Harmonização das Políticas Públicas de Mudanças Climáticas. Fórum Clima - Ação Empresarial sobre mudanças Climáticas. Relatório. Marchiori, P. (Ed.). São Paulo. p. 44. abr. 2012. Disponível em: <http://www3.ethos.org.br/cedoc/o-desafio-da-harmonizacao-das-politicaspublicas-de-mudancas-climaticas-forum-clima-abril-2012/\#.VhapRvlVhBf $>$. Acesso em: abr. 2015.

Haldén, P. The Geopolitics of Climate Change: Challenges to the International System. FOI - Swedish Defence Research Agency: Stockholm, 2007. 171 p. Disponível em:<http://www.iaea.org/inis/collection/NCLCollectionStore/ Public/39/036/39036330.pdf>. Acesso em: jul. 2015.

Halonen, M.; Ryynänen,E.; Sorasahi,H.Vihma, A.;Kanninnen, M.Globalemission reduction potential of additional mitigation measures. Innovative Solutions for Sustainability, Gaia Consulting Oy, The Finish Institute of International Affairs, University of Helsinki: Helsinki, 2013. Disponível em: <http://www.ym.fi/ download/Global_emission_reduction_potential_of_additional_mitigation measures/4d52d710-fbcb-4c76-91f4-d852e1c91fea/92993>. Acessō em: maiō 2015.

Kelman, I. Difficult decisions: Migration from Small Island Developing States under climate change.Migration, Climate Change and SIDS. AGUpublications. Earth'sFuture, v. 3, i. 4, p. 133-142. abr. 2015. Disponível em:<http://onlinelibrary. wiley.com/doi/10.1002/2014EF000278/full>. Acesso em: maio 2015.

KESSELMAN, M.; Krieger, J.; Joseph, W.A. Introduction to Comparative Politics: Political Challenges and Changing Agendas. CENAGE Learning. 7th Ed. p.724. 2015.

MCManus, K. The principle of 'common but differentiated responsibility' and the UNFCCC. Climatico Special Features, 2009. Disponível em: <http://www. mercyworld.org/_uploads/_cknw/files/2012/Link3.pdf >. Acesso em: out. 2015.

Pattberg, P.; Wilderberg, O. Theorising Global Environmental Governance: Key Findings and Future Questions. Forum: Global Governance in the Interregnum. Millennium: Journal of International Studie, v. 43. i.2, p.684-705. 2015. Disponível em:<file://C:/Users/carloshp/Documents/Downloads/Pattberg_ Widerberg_Millennium_2015.pdf>. Acesso em: out. 2015.

paraíba (estado). Lei n 9.336 de 31 de Janeiro de 2011. Institui a Política Estadual de Mudanças Climáticas - PEMC do Estado da Paraíba. Ato do Poder Legislativo. 
Estado da Paraíba. p. 8. 31 jan. 2011. Disponível em: <http://proclima.cetesb. sp.gov.br/wp-content/uploads/sites/28/2014/08/lei_9336_310111_pb.pdf >. Acesso em: maio 2015.

. Decreto n. 43.216 de 30 de Setembro de 2011. Regulamenta a Lei ${ }^{0}$ 5.690, de 14 de Abril de 2010, que dispõe sobre a Política Estadual sobre Mudança Global do Clima e Desenvolvimento Sustentável. Governo do Estado do Rio de Janeiro. Diário Oficial do Estado do Rio de Janeiro. Ano XXXVII, nº 186. 3 out. 2011. Disponível em:<http://download.rj.gov.br/documentos/10112/1403799/ DLFE59683.pdf/DOERJ_43216_Clima.pdf>. Acesso em: fev. 2015.

. Lei n 5.690 de 14 de abril de 2010. Institui a Política Estadual sobre Mudança Global do Clima e Desenvolvimento Sustentável e dá Outras Providências. Governo do Estado do Rio de Janeiro. Projeto de Lei $\mathrm{n}^{\circ}$ 755A/2007. Rio de Janeiro, 14 abr. 2010. Disponível em:<http://download.rj.gov.br/ documentos/10112/1312221/DLFE-56318.pdf/LEIN5690.pdf $>$. Acesso em: ago. 2015.

são paulo (estado). Lei n 13.798 de 9 de Novembro de 2009. Institui a Política Estadual de Mudanças Climáticas - PEMC. Estado de São Paulo. p. 25. 9 dez. 2009. Disponível em:<https://docs.google.com/document/ d/1 kofB326LmTGHgN8gKGZiYPRGC_cbXvHe5ea8e1R42tk/edit?hl=en_ US\&pli=1>. Acesso em: maio 2015.

SEEG (Sistema de Estimativas de Emissões de Gases do Efeito Estufa). A análise das emissões de GEE no Brasil (1970-2013) e suas implicações para políticas públicas. Governos Locais pela Sustentabilidade (ICLEI). São Paulo: Observatório do Clima, 2015. 52 p. Disponível em: < https://s3-sa-east-1.amazonaws.com/seeg. tracersoft.com.br/wp-content/uploads/2015/08/sintese_2015.pdf >. Acesso em: ago. 2015.

UNFCCC (United Nations Framework Convention on Climate Change). Parties \& Observers. New York: United Nations. p.1. 2014. Disponível em:<http://unfccc. int/parties_and_observers/items/2704.php>. Acesso em: 21 out. 2015.

WRI (World Resources Institute). Total GHG Emissions Including Land-Use Change and Forestry - 2012. CAIT Climate Data Explorer, 2012. Disponível em: <http://cait.wri.org/>. Acesso em: set. 2015.

Carlos Germano Ferreira Costa - Possui Graduação em Agronomia pela Universidade Federal do Ceará. Especialização em GEOGRAPHY/POLP/TIMOR 1 pela Universidade Nacional do Timor Leste. Mestrado em Ecologia e Recursos Naturais pela Universidade Federal do Ceará e Doutorado em Desenvolvimento e Meio Ambiente pela mesma Universidade. Atualmente é professor na Universidad Politécnica de Madrid.

Recebido para publicação em 12 de outubro de 2015 Aceito para publicação em 29 de novembro de 2015 